\title{
A inserção do assistente social na atenção primária à saúde
}

\author{
The insertion of the social worker into the primary health care
}

\author{
Débora MARTINI* \\ Keli Regina DAL PRÁ**
}

\begin{abstract}
Resumo: Este estudo objetiva refletir sobre a inserção dos assistentes sociais na área da saúde, especialmente na Atenção Primária em Saúde (APS), a partir da criação dos Núcleos de Apoio à Saúde da Família (NASF). Desenvolveram-se uma revisão de literatura sobre a intervenção profissional no primeiro nível de atenção do Sistema Único de Saúde (SUS) e uma pesquisa documental por meio de análise de leis, decretos e portarias que norteiam a intervenção do assistente social no NASF e a gestão da política de saúde na APS. Como principais resultados destacam-se os muitos desafios a serem superados pelo profissional nesse campo de atuação, que vão desde a precarização do trabalho até as tentativas de desmonte da política de saúde lançadas atualmente.

Palavras-chave: Serviço Social. Sistema Único de Saúde. Atenção Primária em Saúde. Saúde da Família.
\end{abstract}

\begin{abstract}
Este estudo objetiva refletir sobre a inserção dos assistentes sociais na área da saúde, especialmente na Atenção Primária em Saúde (APS), a partir da criação dos Núcleos de Apoio à Saúde da Família (NASF). Desenvolveram-se uma revisão de literatura sobre a intervenção profissional no primeiro nível de atenção do Sistema Único de Saúde (SUS) e uma pesquisa documental por meio de análise de leis, decretos e portarias que norteiam a intervenção do assistente social no NASF e a gestão da política de saúde na APS. Como principais resultados destacam-se os muitos desafios a serem superados pelo profissional nesse campo de atuação, que vão desde a precarização do trabalho até as tentativas de desmonte da política de saúde lançadas atualmente. Keywords: Social Work, Unified Health System (SUS), Primary Attention in Health, Family Health.
\end{abstract}

Submetido em: 12/1/2018. Aceito em: 17/2/2018.

\section{INTRODUÇÃO}

A saúde foi a área que, historicamente, absorveu o maior número de profissionais de Serviço Social no Brasil, principalmente a partir da década de 1940, com a elaboração de um conceito de saúde que passou a considerar também os aspectos biopsicossociais como seus determinantes e a elaboração de uma política de saúde centrada na assistência médica hospitalar e curativa (CORREIA, 2005).

Ao longo da história da política de saúde, a intervenção dos assistentes sociais refletiu seu processo de amadurecimento teórico-metodológico, perpassando desde a perspectiva mo-

\footnotetext{
* Assistente Social. Mestre em Serviço Social pela Universidade Federal de Santa Catarina. Assistente Social do Núcleo de Apoio a Saúde da Família (NASF) da Secretaria Municipal de Saúde de Florianópolis (SMS, Florianopólis (SC), Brasil). Av. Prof. Henrique da Silva Fontes, 6100, Trindade, Florianópolis (SC), CEP: 88036-700. E-mail: <deb_martini@yahoo.com.br>. ORC ID: <http://orcid.org/oooo-ooo1-9191-7858>. ** Assistente Social. Doutora em Serviço Social pela Pontifícia Universidade Católica do Rio Grande do Sul. Professora do Departamento de Serviço Social da Universidade Federal de Santa Catarina (UFSC, Florianopólis (SC), Brasil). Endereço da instituição: Campus Reitor João David Ferreira Lima, s/n, Trindade, Florianópolis (SC), CEP: 88040-900. E-mail: <keli.regina@ufsc.br>. ORC ID: <http://orcid.org/oooo0002-1470-7811>.
} 
dernizadora até a vertente da Intenção de Ruptura, que passou a direcionar a renovação do Serviço Social (BRAVO, 2004; BRAVO; MATOS, 2001). Mesmo reconhecendo que, de imediato, a perspectiva da Intenção de Ruptura não influenciou significativamente o Serviço Social na área da saúde, visto que os profissionais, majoritariamente, não se engajaram no Movimento Sanitário, foi possível identificar a sensibilização de assistentes sociais para o campo da saúde coletiva (CORREIA, 2005; BRAVO, 2011).

O engajamento dessa categoria profissional e a defesa da saúde como um direito social universal se expressa com clareza a partir de fins da década de $1980 \mathrm{com}$ a promulgação da Constituição Federal de 1988 e a implantação do Sistema Único de Saúde (SUS). O SUS trouxe como inovações a ampliação do conceito de saúde e os princípios de descentralização, integralidade e participação da comunidade. Essas inovações influenciaram o novo modelo de assistência à saúde, voltado para a promoção e superação do modelo centrado na doença e nas ações curativas, e requisitou um trabalho multiprofissional, no qual o assistente social passou a ter maior importância na área da saúde (CORREIA, 2005).

No entanto, mesmo com as mudanças de ordem tecnológica, organizacional e política, a atual organização do SUS, ao passo que atende a algumas reivindicações históricas do Movimento Sanitário, não supera as contradições existentes, entre as quais constam a precariedade de recursos, a qualidade e quantidade dos atendimentos, a burocratização e a ênfase na assistência médica curativa (COSTA, 200o).

É nesse contexto que emerge um conjunto de requisições expressivas da tensão entre as ações tradicionais da saúde e as novas proposições do SUS, determinando inclusive o âmbito de atuação do assistente social. Entre tais requisições, destacam-se: a) as derivadas do histórico déficit de oferta dos serviços para atender às necessidades de saúde da população; b) as relacionadas às inovações gerenciais, tecnológicas e técnico-políticas implementadas no SUS; e c) as relacionadas com a adaptação dos usuários e profissionais à atual estrutura do SUS (COSTA, 200o). Pode-se dizer, com isso, que as principais demandas dentro do sistema de saúde advêm das contradições presentes no seu processo de racionalização/reorganização, determinado principalmente pela hierarquização do SUS por níveis de complexidade, pela sua descentralização e democratização.

O processo de municipalização do SUS incentivou a alocação dos profissionais mais próximos aos usuários. Essa descentralização administrativa proporcionou uma crescente ampliação do mercado de trabalho para as profissões da área da saúde na esfera municipal, entre elas o serviço social (KRUGER, 2010). O aumento na contratação de assistentes sociais em todos os níveis de atenção, principalmente de média e alta complexidade, tornou-se uma tendência, causada pelo rebatimento da reforma do Estado na política de saúde, e está vinculado ao crescimento exponencial de demandas aos serviços de saúde (SOARES, 2010).

Esse fato expressa as contradições do SUS e sua racionalidade hegemônica, tendo em vista que a política de saúde, mesmo tendo como uma de suas principais diretrizes a centralidade na Atenção Primária em Saúde (APS) e, dentro desta, a Estratégia de Saúde da Família (ESF), implantada nos anos de 1990, tem a maior parte dos assistentes sociais trabalhando nos serviços de média e alta complexidade; ou seja, apesar de a trajetória da profissão na saúde ter possibilitado a aquisição de conhecimentos que qualificaram o profissional para atuar na

Argum., Vitória, v. 10, n. 1, p. 118-132, jan./abr. 2018. 
equipe de saúde como articulador do recorte do social (NOGUEIRA, 2005) e de serem abertos novos espaços de atuação depois do SUS, possibilitando a prática em trabalho multiprofissional, interdisciplinar e intersetorial, a atuação do Serviço Social nas últimas décadas permanece centrada na atenção hospitalar.

A partir dessas considerações iniciais, objetiva-se refletir sobre a inserção dos assistentes sociais na APS a partir da implementação dos Núcleos de Apoio à Saúde da Família (NASF). Essa reflexão desenvolveu-se metodologicamente por meio de revisão de literatura de caráter narrativa, que, apesar de não utilizar critérios explícitos e sistemáticos para a busca e análise crítica da literatura, é indicada para a fundamentação teórica de trabalhos científicos. Assim, foram utilizadas diversas bases de dados para o levantamento dos artigos a serem estudados, como a base de dados da Scientific Electronic Library Online (Scielo), o portal de periódicos da Coordenação de Aperfeiçoamento de Pessoal de Nível Superior (CAPES) e artigos publicados em livros, no período de 2008 a 2016.

Foi realizada também uma pesquisa documental, por meio de análise de leis, portarias, instruções normativas e cadernos de orientações que norteiam a intervenção do assistente social no NASF e a gestão da política de saúde na APS, publicados no período de 2008 a 2016. Entre os documentos analisados, encontram-se as portarias que criaram a Política Nacional de Atenção Básica, as portarias e cadernos que tratam sobre o NASF e os parâmetros de atuação do assistente social na área da saúde.

A coleta de dados da pesquisa documental foi realizada buscando-se a temática da intervenção profissional do assistente social no campo das políticas sociais, em especial na saúde no primeiro nível de complexidade do SUS, como forma de identificar e analisar informações, materiais e documentos que auxiliaram na identificação das principais características do objeto em questão.

Todos os documentos foram analisados através da técnica de análise de conteúdo (BARDIN, 1979), organizada em três etapas: a) pré-análise - organização do material coletado; b) descrição analítica - estudo aprofundado do material coletado, tendo como base os referenciais teóricos e as questões norteadoras da pesquisa; e c) interpretação referencial - feita com base no suporte teórico da pesquisa.

A estruturação deste artigo inicialmente aborda o contexto da APS no Brasil a partir de sua configuração primeira, desde a década de 1990, para, na sequência, adentrar na particularidade da inserção do assistente social no NASF. Pretende-se contribuir para ampliar e qualificar a discussão acerca da atuação profissional no primeiro nível de complexidade do SUS, levando em conta as tensões presentes na implementação da política social de saúde.

\section{O CENÁRIO DA ATENÇÃO PRIMÁRIA EM SAÚDE}

A APS é compreendida como um conjunto de intervenções, desenvolvidas no âmbito individual e coletivo, que envolve promoção, prevenção, diagnóstico, tratamento e reabilitação em saúde. É desenvolvida por “[...] meio do exercício de práticas gerenciais e sanitárias, democráticas e participativas, sob forma de trabalho em equipe, dirigidas a populações de territórios bem delimitadas, das quais assumem a responsabilidade" (CONSELHO NACIONAL DE

Argum., Vitória, v. 10, n. 1, p. 118-132, jan./abr. 2018. 
SECRETÁRIOS DE SAÚDE, 2004, p. 7). Para Starfield (2002), a APS se diferencia dos demais níveis assistenciais por apresentar estes quatro atributos: atenção ao primeiro contato (ponto de entrada de fácil acesso ao usuário para o sistema de saúde); longitudinalidade (acompanhamento do usuário e sua família ao longo da vida); integralidade (atendimento e ações de saúde realizadas de forma integrada); e coordenação do cuidado (necessidade de os profissionais seguirem responsáveis pelo usuário e seu acompanhamento mesmo quando o atendimento é realizado em outros pontos de atenção da rede de saúde). Esses atributos indicam uma concepção abrangente de APS, e implementá-la implica a construção de sistemas de saúde articulados em rede, centrados no usuário e que respondam às necessidades de saúde da população (GIOVANELLA et al., 2009).

Essa concepção abrangente e integral de APS é relativamente recente, pois, na América Latina, na década de 1980, o termo estava vinculado à abordagem seletiva preconizada pelas agências multilaterais, cuja implementação dos serviços ocorria de forma mínima e em geral com baixa qualidade (CONILL; FAUSTO, 2007; MENDES, 1995). Na agenda de reformas proposta pelo Banco Mundial para os países subdesenvolvidos, encontravam-se: a) o pagamento de taxas pelos usuários dos serviços públicos de saúde, especialmente medicamentos e ações curativas; b) o encorajamento de programas de seguro saúde; c) o uso de recursos não governamentais; e d) a descentralização dos serviços públicos. Dessa forma, os serviços ofertados pelo Estado ficariam restritos a: a) serviços que produzem bens públicos; b) serviços com grande externalidade; c) provimento, direto ou por meio de financiamento, de prestadores privados de serviços de saúde que tenham uma boa relação custo-benefício e uma abordagem socialmente aceitável para reduzir a pobreza; e d) compensação dos problemas e incertezas geradas pelo mercado (MISOCZKY, 1995).

Assim, chamado pejorativamente de cesta básica, o conjunto de ações proposto pelo Banco Mundial orientava que o Estado se incumbisse de um pacote mínimo essencial, que incluiria o cuidado às crianças doentes, planejamento familiar, atenção à gestação e ao parto, o tratamento para doenças sexualmente transmissíveis (DSTs), tuberculose e a oferta - facultativa aos países em desenvolvimento - de serviços para abordar doenças crônicas e degenerativas (FRANCO; MERHY, 2003; MISOCZKY, 1995). As ações de média e alta complexidade ficariam a cargo do setor privado e deveriam ser pagas pelo consumidor. Nessa configuração, o papel do Estado enquanto provedor/financiador de serviços de saúde se resume a garantir o suprimento e a preservação de indivíduos aptos para o mercado de trabalho (MISOCZKY, 1995).

No caso brasileiro, nos anos 1990, foram apontadas falhas na política de saúde, principalmente no que se refere ao atendimento das camadas mais pobres da população e à falta de investimento nas ações do primeiro nível de atenção. Na ocasião, a APS foi o nível prioritário na proposta inicial de reforma do Estado, uma vez que, diagnosticada a escassez de recursos para o financiamento da saúde de modo universal, conforme a Constituição Federal recémaprovada em 1988, seria estabelecido um pacote de serviços clínicos essenciais.

Essa ideia, advinda da década de 1990, tem sido rediscutida recentemente com a privatização da saúde, encaminhada de diversas maneiras pelo governo de Michel Temer. A primeira expressão do privilegiamento da relação com o setor privado tem sido a proposta dos Planos Populares de Saúde, que, com serviços a baixo custo, incentiva parte da população a pagar, 
principalmente por exames e consultas de média complexidade. Esses planos populares têm sido apresentados como a principal alternativa ao desfinanciamento da saúde, promovido pela Emenda Constitucional n. 95/2016, que impõe o novo regime fiscal, ao congelar o financiamento federal do SUS pelos próximos 20 anos, e como alternativa ao atendimento da crescente parcela da população que, ao perder o emprego e a cobertura dos planos privados, retorna ao atendimento no SUS.

Na esteira da desresponsabilização do Estado com a execução dos serviços públicos, está a Parceria Público-Privada, operacionalizada principalmente pelas secretarias estaduais, que repassa os serviços de saúde, principalmente de média e alta complexidade, para a administração de Organizações Sociais (OS). Importante mencionar, porém, que, em alguns municípios no Brasil, a própria APS já passou a ser administrada por OS, com a falácia de reduzir os custos do Estado e ampliar a qualidade dos serviços oferecidos à população. O que se observa, no entanto, é um gasto maior do Estado com o pagamento das OS, que muitas vezes oferecem serviços menos qualificados e mais sucateados, a maior precarização dos vínculos de trabalho dos profissionais que atuam nesses serviços e o desvio dos princípios da APS como a longitudinalidade devido à alta rotatividade de profissionais.

Paralelamente, nos municípios expandem-se os serviços de atenção domiciliar, que preveem o atendimento de pessoas com necessidade de reabilitação, idosos, pacientes crônicos ou em situação pós-cirúrgica no domicílio, com cuidados próximos da família através do suporte de uma equipe multiprofissional de saúde. Sob o slogan da melhoria e ampliação da assistência no SUS aos pacientes com agravos de saúde, que possam receber atendimento humanizado em casa e perto da família, o Programa Melhor em Casa incentiva e normatiza a presença das famílias, através da obrigatoriedade de indicação de um(a) cuidador(a), e afirma o processo de privatização, pois a família, ao ser incorporada na gestão do cuidado, passa a ser "oficialmente" requisitada para tal. Para responder às requisições, as famílias têm basicamente duas alternativas: a contratação/pagamento de cuidadores ou a utilização do trabalho familiar, não pago e invisível, e que continua recaindo majoritariamente sobre as mulheres (MIOTO; DAL PRÁ, 2015).

A partir dessas iniciativas privatizantes, intensificadas no contexto neoliberal mais recente, caberia ao Estado garantir apenas serviços básicos voltados para a APS e para a população que não pudesse arcar com as despesas de saúde via mercado. Foi com essa proposta inicial de racionalização de recursos, a qual tem sido retomada com força na atualidade, que o Brasil, a partir dos anos 1990, passou a investir na APS. Nesse período, no país, o termo APS foi substituído por atenção básica, remetendo ainda mais à lógica da reforma, de atendimento básico, serviços mínimos para a população que não tivesse condições de arcar com os custos de um plano de saúde privado.

No entanto, no Brasil, a pressão do Banco Mundial e o receituário neoliberal encontraram, à época, uma forte ideia de direito público colocada sobre o sistema de saúde, o que culminou na organização do Programa de Agentes Comunitários de Saúde (PACS) e do Programa de Saúde da Família (PSF) como estratégias de mudança do modelo hegemônico (FRANCO; MERHY, 2003). 
O PACS, criado em 1991, teve como objetivo proporcionar à população o acesso e a universalização do atendimento à saúde, através da descentralização das ações e da priorização da promoção da saúde e prevenção de doenças. Teve como inspiração experiências de práticas em saúde, com Agentes Comunitários de Saúde (ACS), que já vinham sendo realizadas em algumas regiões do país (VIANA; DAL POZ, 2005).

Apesar de o objetivo do PACS ser ampliar o acesso à saúde, os ACS eram profissionais com baixo nível de escolaridade, baixa remuneração, sem formação adequada para desempenhar funções de extrema responsabilidade junto à população e, de certa forma, reproduziam a hegemonia médica. Cabia aos ACS realizar visitas domiciliares, que, muitas vezes, eram compulsórias e apresentadas como um grande trunfo, uma vez que se acreditava que essa “[...] intervenção no ambiente familiar é capaz de alterar o perfil 'higiênico' da população e, assim, prevenir os agravos à saúde" (FRANCO; MERHY, 2003, p.57).

Já o PSF visava à reorganização da prática assistencial, substituindo o modelo tradicional de assistência por um modelo que priorizasse a atenção centrada na família e uma compreensão ampliada do processo saúde/doença e que voltasse suas ações para além das práticas curativas (BRASIL, 2001). O que se via, segundo Mendes (1995), porém, era um programa que deveria ter os excluídos e as regiões mais pobres como prioridade para seu atendimento; uma equipe de Saúde da Família (eSF) que atuasse em um território de abrangência definido e que desenvolvesse ações focalizadas na saúde, voltadas às famílias e seu habitat, dando ênfase às ações de promoção e prevenção de saúde, sem descuidar do curativo e das ações de reabilitação; e uma equipe que tivesse uma alta resolubilidade e que atuasse com baixos custos diretos e indiretos, sendo econômicos e ao mesmo tempo sociais.

Em outras palavras, o PACS e o PSF foram criados tendo intenções de cunho racionalizador e voltados para a ideia de focalização, distanciando-se do conceito de atenção primária defendido pelos movimentos de saúde (GUIMARÃES, 2010). A partir de 1997, o PSF passou a ser considerado ESF e a concepção do termo APS foi renovada no Brasil, ampliando-se para uma estratégia de ordenação dos serviços e de promoção da equidade em saúde.

A ESF é dirigida às populações de territórios delimitados, pelas quais assume a responsabilidade sanitária, considerando a dinamicidade existente no território em que vivem essas populações (BRASIL, 2017). Cabe destacar que, atualmente, a ESF é considerada uma estratégia da Política de Atenção Básica, legitimada pela Portaria no 2.436, de 21 de setembro de 2017 (BRASIL, 2017), que também regulamenta os NASF. Estrutura-se a partir das Unidades Básicas de Saúde (UBS), que trabalham com base nos princípios de integralidade e hierarquização, territorialização e adscrição da clientela e equipe multiprofissional. Há que se mencionar, porém, que esses princípios, em alguns momentos, ainda são interpretados sob a ótica higienista, não conseguindo modificar o modelo assistencial e desarticulando sua potência transformadora.

Em relação ao trabalho multiprofissional, embora a equipe seja composta por diferentes profissionais, nada garante que na prática da ESF haverá ruptura com a dinâmica médico centrada. Inicialmente, o PSF e a própria ESF foram pensados com uma equipe mínima, sendo ampliada apenas em 2008, através do NASF. Mesmo com essa ampliação, a regulação do 
acesso aos profissionais do NASF ainda continua centrada na figura do médico e do enfermeiro, sendo o NASF, muitas vezes, não considerado parte integrante da APS.

Mesmo diante desses problemas, a ESF aparece na política de saúde no Brasil com capacidade de seduzir amplas camadas da população carente de assistência (FRANCO; MERHY, 2003). E não somente a população mas os próprios formuladores e gestores do SUS também participaram do Movimento da Reforma Sanitária, isso porque há raízes comuns entre as propostas deste e a ESF, principalmente no que se refere: a) às bases conceituais da epidemiologia e da vigilância em saúde; b) ao fato de a ESF articular um discurso de conotação populista, propondo um mecanismo efetivo de inclusão da população no acesso à saúde; e c) à facilidade de os municípios acessarem os recursos financeiros oriundos do Ministério da Saúde.

Segundo dados do Cadastro Nacional de Estabelecimentos de Saúde (CNES), no ano de 2014, o SUS contava com 44.664 UBS em funcionamento, sendo os serviços de APS em sua maioria (96\%) públicos municipais (ALMEIDA, 2014). Em outubro de 2016, dados do DATASUS indicavam que, no Brasil, havia implantadas $41.007 \mathrm{eSF}$, gerando uma estimativa de cobertura populacional de aproximadamente $64,67 \%$. Em relação ao NASF, havia no território nacional 2.582 NASF tipo 1; 899 NASF tipo 2; 1059 NASF tipo 3; e 27 NASF intermunicipais.

Esses números apontam o avanço da ESF desde a regulamentação do SUS, porém, indicam também para a necessidade de se avançar em relação à implementação da APS no Brasil, visando: a) a melhoria da cobertura populacional; b) mudar os sujeitos que se colocam como protagonistas desse modelo de assistência, como forma de associar tanto novos conhecimentos técnicos, novas configurações tecnológicas do trabalho em saúde, quanto outra micropolítica para que este trabalho transforme as práticas em saúde; c) e à remodelação, por parte dos profissionais, da assistência à saúde, modificando também seus processos de trabalho, repensando a forma de produzir o cuidado e modificando seu modo de agir entre si e com os usuários.

\section{REFLEXÕES SOBRE A INSERÇÃO DO ASSISTENTE SOCIAL NA APS A PARTIR DO NASF}

Os profissionais de Serviço Social, apesar da forte tradição e legitimidade na área da saúde, tiveram atuações no âmbito municipal e na APS muito restritas. A inserção profissional na APS ocorreu de forma heterogênea no território nacional, principalmente após a criação da ESF, com iniciativas isoladas de inserção nas equipes mínimas. Isso se deu principalmente pelo fato de o assistente social não compor a equipe da ESF e por estar a cargo de cada município a complementação das equipes com outras categoriais profissionais. Mais recentemente, com a criação e regulamentação do NASF, a inserção dos assistentes sociais foi ampliada $^{1}$, mas não sem grandes discussões entre a categoria profissional, que sempre defendeu o profissional como equipe mínima da ESF.

${ }^{1}$ Segundo Guimarães (2010), o Serviço Social é a terceira profissão com o maior número de profissionais nos NASF. 
O NASF foi criado em 2008 e é constituído por uma equipe de profissionais de diversas áreas do conhecimento que atuam em conjunto com as eSF visando ampliar a resolubilidade das ações na APS. Cabe aos gestores municipais e às eSF, mediante critérios de prioridades identificadas a partir de necessidades locais, compor a equipe do NASF. Essa equipe multiprofissional deve atuar dentro das diretrizes da APS, como: ação interdisciplinar e intersetorial, educação permanente em saúde dos profissionais e da população, desenvolvimento de ações no território, integralidade, participação social, educação popular, promoção da saúde e humanização (BRASIL, 2010).

A organização dos processos de trabalho do NASF tem como foco o território sob sua responsabilidade e, por não ser porta de entrada do SUS, os profissionais devem atuar como retaguarda especializada das eSF, desenvolvendo um trabalho compartilhado e colaborativo de acordo com suas necessidades (BRASIL, 2014). Assim, o NASF é uma estratégia de organização que deve orientar-se pelo referencial do apoio matricial (matriciamento), que significa, em síntese, “[...] um novo modo de produzir saúde em que duas ou mais equipes, num processo de construção compartilhada, criam uma proposta de intervenção pedagógicoterapêutica" (CHIAVERINI, 2011, p.13).

Entende-se o apoio matricial como um dispositivo que visa à superação das práticas tradicionais em saúde e da racionalidade gerencial hegemônica, por meio do desenvolvimento de ações de apoio que são capazes de criar linhas transversais nas estruturas dos serviços e equipes de saúde (CAMPOS; DOMITTI, 2007).

O processo constitutivo do conceito de matriciamento tem como base a necessidade de contrapor os processos de trabalho em saúde e a clínica estabelecida até então, que se submetiam à lógica de trabalho pautada na autoridade, na verticalização, com esquemas de decisão e poder assimétricos (CAMPOS; DOMITTI, 2007). Lógica essa também pautada no fordismo e na inspiração taylorista, segundo os quais as tarefas e procedimentos visando ao aumento da eficiência ao nível operacional só eram garantidos a partir do adestramento do trabalhador para o desenvolvimento de uma função específica, com trabalho dividido e repetitivo; ou seja, os profissionais devem "[...] construir estratégias para lidar com a realidade e inserir-se em práticas de apoio no campo da saúde coletiva, com ênfase nos processos de compartilhamento de saberes [...]"(SANTOS; LANZA, 2014, p. 239) entre a equipe NASF e a eSF.

Em outros termos, o matriciamento visa transformar a lógica tradicional - verticalizada dos sistemas de saúde em uma lógica horizontal, mais eficaz para a ampliação do campo de atuação das eSF e qualificação de suas ações (CHIAVERINI, 2011). Isso não quer dizer que algumas práticas tradicionais, como encaminhamentos, referência e contrarreferência, deixaram de existir, ao contrário, esses instrumentos são necessários para o ordenamento do cuidado pela eSF, principalmente porque são práticas necessárias para a integralidade do cuidado em saúde.

Vale destacar, porém, que, por ser uma prática nova no SUS, o matriciamento ainda possui resistências em sua implantação, seja por parte da gestão do SUS, seja por parte dos profissionais de saúde. Em relação à gestão do SUS, o incentivo à produtividade é o principal obstáculo a ser superado, visto que o foco dos profissionais do NASF, para a gestão, deve ser a dimensão clínico-assistencial e um processo de trabalho centrado em procedimentos. Para

Argum., Vitória, v. 10, n. 1, p. 118-132, jan./abr. 2018. 
eles, momentos de discussão de casos, reuniões entre eSF e profissionais do NASF e educação permanente não são eficazes para a resolutividade dos problemas da APS e por isso devem ser evitados. Em relação aos profissionais que atuam na APS, observam-se dificuldades no compartilhamento dos saberes e intervenções, fazendo com que operem numa lógica biomédica e corporativista. Também se observa uma lógica de trabalho pautada na autoridade, com esquemas de decisão e poder assimétricos, na qual os profissionais da eSF acreditam que são os únicos responsáveis pelos usuários e por isso podem atuar sozinhos; os profissionais do NASF, por sua vez, ao receberem uma situação para atendimento, acreditam que o usuário passa a ser de sua responsabilidade, não compartilhando com a equipe de referência o andamento do acompanhamento do usuário.

Associado a essas dificuldades, muitas categorias, entre elas o Serviço Social, criticavam o modelo NASF criado, visto que o assistente social poderia ser considerado um paramédico, e somente seria demandado quando o profissional da equipe mínima necessitasse. Essa forma de trabalho dificulta e restringe a atuação do profissional, que passa a atuar de acordo com as necessidades e demandas de outro profissional, que, na maior parte das vezes, tem dificuldades de compreender a atuação do assistente social. O matriciamento, portanto, apesar de ter sido criado para inovar e horizontalizar as práticas na APS, ainda precisa vencer inúmeros obstáculos, visando tornar-se uma prática que realmente potencialize o cuidado nesse nível de complexidade do SUS.

Com base no exposto, as ações desenvolvidas pelo NASF possuem, então, via de regra, dois principais públicos-alvo: as equipes de referência apoiadas e, diretamente, os usuários do SUS, e devem ser feitas em, pelo menos, duas dimensões: clínico-assistencial e técnicopedagógica (BRASIL, 2014). A primeira incide sobre ações diretas com os usuários e a segunda produz ação de apoio educativo com e para as equipes. Em se tratando da estrutura, essas ações devem ser divididas em: compartilhadas na UBS, compartilhadas no território e ações específicas dos profissionais do NASF (BRASIL, 2010).

As ações compartilhadas na UBS visam a uma intervenção interdisciplinar, com troca de saberes, capacitação e responsabilidades mútuas. Entre as ações que se destacam estão os estudos e discussões de casos e situações, a realização de projetos terapêuticos singulares, orientações, realização de reuniões e atendimentos conjuntos. As ações compartilhadas no território devem ser realizadas de forma articulada com as eSF, sendo possível o desenvolvimento de projetos de saúde no território, planejamentos, reuniões, apoio a grupos, trabalhos educativos e de inclusão social, enfrentamento de situações de violência e ruptura social, e ações junto aos equipamentos públicos. Já as ações específicas do profissional NASF com usuários e/ou famílias devem ser precedidas de encaminhamento por parte da eSF, com discussões e negociação a priori entre os profissionais responsáveis pela situação. Segundo orientações do Ministério da Saúde, o atendimento direto e individualizado pelo profissional NASF ocorrerá apenas em situações extremamente necessárias (BRASIL, 2010).

A constituição de uma rede de cuidados também é uma das estratégias essenciais dentro da lógica do NASF, sendo responsabilidade da equipe NASF, juntamente com a eSF, criar espaços de discussão internos e externos visando ao aprendizado coletivo e à superação da lógica fragmentada da saúde para a construção de redes de atenção e cuidado. 
Tendo como base as orientações para a atuação do NASF e sendo a integralidade sua principal diretriz, entende-se que é de extrema importância a atuação do assistente social nesse espaço, principalmente ao se compreender a integralidade em seus três sentidos:

[...] (a) a abordagem integral do indivíduo levando em consideração seu contexto social, familiar e cultural e com garantia de cuidado longitudinal; (b) as práticas de saúde organizadas a partir da integração das ações de promoção, prevenção, reabilitação e cura; além de (c) a organização do sistema de saúde de forma a garantir o acesso às redes de atenção, conforme as necessidades de sua população (BRASIL, 2010, p. 16).

Levando-se em conta a integralidade, a eSF precisa compreender o indivíduo e a comunidade numa visão abrangente, que leve em conta o contexto onde estão inseridos. Também pressupõe realizar processos de territorialização, de planejamento participativo, de fortalecimento dos espaços de controle social para além da intervenção apenas no processo saúdedoença. A inclusão do assistente social, portanto, é fundamental, na medida em que sua atuação na APS é organizada a partir dos princípios do SUS.

O assistente social inserido na APS, por meio do NASF, respaldado pelos princípios do seu Projeto Ético-Político e da Reforma Sanitária, tem subsídios para realizar seu trabalho na perspectiva da universalidade de acesso, segundo a qual todos devem receber atendimento, independentemente de raça, classe social, religião, etc.; e da integralidade da assistência, que preconiza que seja considerada, por todos os profissionais da saúde, a realidade econômica e social do usuário, visando, com isso, a um atendimento articulado e contínuo das ações e serviços de saúde. Também contribui levantando dados sobre a realidade socioeconômica dos usuários, divulgando e propiciando o acesso às informações pelos usuários, visto que o assistente social tem a seu favor sua prática educativa, que traz a informação perpassada em todas as suas atividades; e incentivando a participação da comunidade junto a órgãos legitimados de participação e controle social, ampliando com isso seu campo de atuação.

Nessa lógica, o profissional pode contribuir para a participação social, a acessibilidade, o vínculo e a integralidade da atenção, uma vez que desenvolve ações de cunho educativo na prestação de serviços sociais que viabilizam o acesso aos direitos e aos meios de exercê-los, cooperando para que as necessidades e os interesses dos sujeitos de direito ganhem visibilidade na cena pública e possam ser reconhecidos. Assim, os profissionais afirmam o compromisso com os direitos e interesses dos usuários e com a qualidade dos serviços prestados (IAMAMOTO, 2006).

O profissional de Serviço Social, através da sua prática político-pedagógica, insere-se em processos de luta pela defesa e ampliação dos direitos, mediante garantia de princípios de universalização das políticas sociais e democratização da gestão estatal. Seu exercício profissional está pautado em ações que socializam informações e alargam canais de incentivo à participação e ao controle social por parte da sociedade civil, permitindo ampliar sua possibilidade de ingerência na coisa pública (IAMAMOTO, 2004).

Pode-se afirmar, portanto, que o assistente social é um profissional que pode contribuir significativamente na APS, uma vez que sua atuação contribui para a ampliação do olhar sobre 
a saúde, tendo como base as determinações sociais da saúde, e contribui para a construção de redes de suporte social, imprescindível para o trabalho do NASF.

A inclusão do assistente social no NASF também está em consonância com os princípios éticos e políticos da profissão e do projeto de Reforma Sanitária, e suas ações deverão situar-se como espaço de promoção da cidadania e de produção de estratégias que fomentem e fortaleçam redes de suporte social, propiciando maior integração entre serviços sociais e outros equipamentos públicos e os serviços de saúde nos territórios adscritos, contribuindo para o desenvolvimento de ações intersetoriais que visem ao fortalecimento da cidadania (BRASIL, 2010). Não é à toa, portanto, que, junto ao NASF, o assistente social é chamado para atuar em ações de intersetorialidade, articulação de redes sociais e da participação cidadã, e sua atuação deve partir da compreensão de que o direito à saúde se faz pela promoção da cidadania. Suas ações junto às eSF devem voltar-se, portanto, para articulações intersetoriais, educação e mobilização em saúde e formação de redes de proteção social (BRASIL, 2010). O trabalho interdisciplinar e integrado com as demais equipes também se torna fundamental junto ao NASF.

A área estratégica do Serviço Social no NASF se constrói com base no espaço do território onde se encontram os indivíduos, suas famílias, a comunidade, os equipamentos sociais públicos e privados e uma infinidade de redes que o tornam um espaço vivo e dinâmico. Sendo assim, a territorialização e a adscrição da população às eSF também são diretrizes que podem ser estimuladas pelo assistente social.

Segundo Sodré (2010), o território tornou-se foco da ação da APS e os hábitos e as manifestações da cultura local são parte dos determinantes sociais da saúde. Nesse sentido, as dinâmicas dos territórios são dinâmicas locais com influências das políticas mundializantes, visto que a cultura se manifesta nessa diversidade e os hábitos tornam-se fonte primária para trabalhar a saúde como produto final da ação profissional. Em outras palavras, o trabalho junto ao território requer uma ação política por excelência e “[...] dinamizar redes, ativar e conhecer as dinâmicas produtivas dos territórios, conhecer hábitos e cotidianeidade da coletividade [...]" (SODRÉ, 2010, p. 464) tornam-se um trabalho característico do profissional de Serviço Social.

A aproximação territorial favorecida pela ESF propicia uma interação maior com o usuário e maior potencialidade de intervenção referente às expressões da questão social, pelo fato de que, ao se observar os complexos (culturais, históricos, políticos, entre outros) que compõem a totalidade apreendida, uma vez que o contato permanece contínuo, é possível desenvolver um planejamento mais assertivo para intervenção na realidade local, evitando ações emergenciais e burocráticas por parte do profissional; mas ainda tem-se que vencer a barreira do quantitativo de profissionais na APS. Ampliar o número de assistentes sociais nas unidades de saúde é fundamental para garantir não somente uma atenção primária abrangente como o conceito ampliado de saúde.

\section{CONSIDERAÇÕES FINAIS}

Ao longo da história da política de saúde, a intervenção dos assistentes sociais refletiu seu processo de amadurecimento, ampliando inclusive sua inserção nos diferentes níveis de

Argum., Vitória, v. 10, n. 1, p. 118-132, jan./abr. 2018. 
complexidade do SUS. Durante essa trajetória, o profissional passou a ter maior importância na política de saúde, fato que exigiu do profissional, em inúmeros momentos, resistência e luta para a manutenção de um sistema universal, público, gratuito e de qualidade.

Com a criação do NASF, o assistente social passou a estar presente em maior número da APS e os desafios para a atuação profissional nesse novo campo tornaram-se mais evidentes, passando pela defesa da categoria para o profissional ser inserido na equipe mínima da ESF, pela lógica do matriciamento e pela crítica ao papel de paramédico. Para além desses desafios, porém, o profissional inserido na APS tem subsídios para ampliar sua atuação visando atender aos princípios do SUS: da universalidade, do acesso, da integralidade da assistência, do acesso à informação e da defesa ao direito à saúde dos usuários.

Atuando com base no Projeto Ético-Político profissional e no projeto da Reforma Sanitária, o assistente social deve atuar de modo a defender a política de saúde das inúmeras tentativas de precarização, promovendo a cidadania, a participação e o controle social. É fundamental destacar, porém, que ainda se faz necessário que o profissional esteja presente de forma mais ampla e qualificada na APS e que, apesar de o NASF ser um espaço de inserção profissional formalmente criado pelo Ministério da Saúde, não pode ser considerado como o mais adequado, fazendo com que se defenda a inserção do assistente social nas eSF.

Especificamente na APS, ao longo dos anos houve avanços em relação à abordagem inicial preconizada pelas agências multilaterais, porém, atualmente, com as propostas de privatização da saúde encaminhadas pelo atual governo, tem-se trazido à tona o privilegiamento do setor privado, o desfinanciamento da saúde e a desresponsabilização do Estado com a execução das políticas públicas, em especial na área da saúde. Como consequência, o que tem sido observado é cada vez mais a precarização do SUS e dos vínculos de trabalho dos profissionais que atuam nesses serviços. Cabe, portanto, ao profissional inserido nesse espaço, apesar de todos os desafios encontrados, desenvolver suas habilidades críticas e criativas visando à criação de espaços de participação social e mobilização social com vistas a lutar em prol dos direitos sociais conquistados a partir da Constituição Federal de 1988 e que se encontram sob ameaça.

\section{REFERÊNCIAS}

ALMEIDA, P. F. Instituto Suramericano de Gobierno en Salud. Mapeamento e análise dos modelos de Atenção Primária à Saúde nos países da América do Sul: atenção primária à saúde no brasil. Rio de Janeiro, 2014. Disponível em: <http://isagsunasur.org/publicacao/mapeamento-e-analise-dos-modelos-de-atencao-primaria-saudenos-paises-da-america-do-sul-atencao-primaria-saude-no-brasil/>. Acesso em: 26 dez. 2017.

BARDIN, L. Análise de conteúdo. Lisboa: Edições 70, 1979.

BRASIL. Ministério da Saúde. Programa de Saúde da Família. Brasília (DF), 2001.

BRASIL. Ministério da Saúde. Diretrizes do NASF: Núcleo de Apoio a Saúde da Família. Brasília (DF), 2010. (Caderno de Atenção Básica, n. 27). Disponível em: 
<http://189.28.128.100/dab/docs/publicacoes/cadernos_ab/abcad27.pdf>. Acesso em: 5 dez. 2017.

BRASIL. Ministério da Saúde. Núcleo de Apoio à Saúde da Família: Ferramentas para a gestão e para o trabalho cotidiano. Brasília (DF), 2014. (Cadernos de Atenção Básica, no 39). Disponível em: <http://189.28.128.10o/dab/docs/portaldab/publicacoes/caderno_39.pdf>. Acesso em: 28 dez. 2017.

BRASIL. Portaria no 2.436, de 21 de setembro de 2017. Aprova a Política Nacional de Atenção Básica, estabelecendo a revisão de diretrizes para a organização da Atenção Básica, no âmbito do Sistema Único de Saúde (SUS). Diário Oficial [da] União, Poder Executivo, n. 183, Brasília (DF), 22 set. 2017. Seção 1, p. 68. Disponível em:

$<$ http://pesquisa.in.gov.br/imprensa/jsp/visualiza/index.jsp?jornal=1\&pagina=68\&data=22/o 9/2017>. Acesso em: 20 dez. 2017.

BRAVO, Ma Inês; MATOS, M. A Saúde no Brasil: reforma sanitária e ofensiva neoliberal. In: BRAVO, M. I.; PEREIRA, P. (Orgs.). Política e democracia. São Paulo: Cortez; Rio de Janeiro: UERJ, 2001. p. 197-216.

BRAVO, Ma Inês. Conselhos de Saúde e Seguridade Social. In: ENCONTRO NACIONAL DE PESQUISADORES EM SERVIÇO SOCIAL, 9., 2004, Porto Alegre. Anais..., Porto Alegre: ENPESS; ABEPSS, 2004.

BRAVO, M. I. Serviço Social e reforma sanitária: lutas sociais e práticas profissionais. 4. ed. São Paulo: Cortez, 2011.

CAMPOS, G. W. S; DOMITTI, A. C. Apoio Matricial e equipe de referência: uma metodologia para gestão do trabalho interdisciplinar em saúde. Cad. Saúde Pública, Rio de Janeiro, v. 23, n. 2, p. 399-407, fev. 2007.

CHIAVERINI, D. H. (Org.). Guia prático de matriciamento em saúde mental. Brasília (DF): Ministério da Saúde; Centro de Estudo e Pesquisa em Saúde Coletiva, 2011. Disponível em:

<http://bvsms.saude.gov.br/bvs/publicacoes/guia_pratico_matriciamento_saudemental.pdf >. Acesso em: 20 dez. 2017.

CONILL, E. M; FAUSTO, M. C. R. Análisis de la problemática de la integración de la APS en el contexto actual: causas que inciden en la fragmentación de servicios y sus efectos en la cohesión social. Rio de Janeiro: Documento Técnico EuroSocialSalud; 2007. Disponível em: <http://www5.ensp.fiocruz.br/biblioteca/dados/arq6952.pdf>. Acesso em: 1o nov. 2017.

CONSELHO NACIONAL DE SECRETÁRIOS DE SAÚDE. Atenção Primária. Seminário para estruturação de consensos. Cadernos de informação técnica e memória de Progestores. Brasília (DF), 2004. 
CORREIA, M. V. C. Desafios para o controle social: subsídios para capacitação de conselheiros de saúde. Rio de Janeiro: Fiocruz, 2005.

COSTA, M. D. H. O trabalho nos serviços de saúde e a inserção dos(as) assistentes sociais. Revista Serviço Social e Sociedade, São Paulo, n. 62, p. 35-72, mar. 2000.

FRANCO, T. B.; MERHY, E. E. Programa de Saúde da Família (PSF): contradições de um programa destinado à mudança do modelo tecnoassistencial. In: MERHY, E. E. et al. (Orgs.). O trabalho em saúde: olhando e experienciando o SUS no cotidiano. São Paulo: Hucitec, 2003. p. 55-124.

IAMAMOTO, M. V. As Dimensões Ético-políticas e Teórico-metodológicas no Serviço Social Contemporâneo. In: MOTA, A. E. et al. Serviço Social e Saúde: trabalho e formação profissional. Florianópolis, 2006. CD-ROM.

IAMAMOTO, M. V. O Serviço social na contemporaneidade: trabalho e formação profissional. 7. ed. São Paulo: Cortez, 2004.

GIOVANELLA, L. et al. Saúde da família: limites e possibilidades para uma abordagem integral de atenção primária à saúde no Brasil. Ciência e Saúde Coletiva, Rio de Janeiro, v. 14, n. 3, p. 783-794, maio/jun. 2009.

GUIMARÃES, E. M. S. Serviço social e saúde da família: perspectivas de inserção e prática profissional. 2010. 153 f. Dissertação (Mestrado em Serviço Social)-Programa de PósGraduação em Serviço Social, Universidade do Estado do Rio de Janeiro, Rio de Janeiro, 2010.

KRUGER, T. R. Serviço Social e Saúde: espaços de atuação a partir do SUS. Serviço Social e Saúde, Campinas, v. 9, n. 2, p. 123-145, jul./dez. 2010.

MENDES, E. V. et al. Distrito sanitário: o processo social de mudança das práticas sanitárias do Sistema Único de Saúde. 3. ed. São Paulo: HUCITEC; Rio de Janeiro: ABRASCO, 1995.

MIOTO, R. C. T.; DAL PRÁ, K. R. Serviços sociais e responsabilização da família: contradições da política social brasileira. In: CAMPOS, M. S. C.; CARLOTO, C. M. MIOTO, R. C. T. (Org.). Familismo, direitos e cidadania: contradições da política social. São Paulo: Cortez, 2015. p. 147-178.

MISOCZKY, M. C. A agenda para reformas do Banco Mundial e a política de saúde: algumas notas para reflexão. Saúde em Debate, Londrina, n. 47, p. 4-7, 1995.

NOGUEIRA, V. M. O Serviço Social na área da Saúde. Florianópolis: UFSC, 2005. Trabalho não publicado.

SANTOS, E. R.; LANZA, L. M. B. O matriciamento no NASF: interpretações sobre o trabalho do Assistente Social. Argumentum, Vitória, v. 6, n. 2, p. 233-246, jul./dez. 2014. Disponível em: http://periodicos.ufes.br/argumentum/article/view/8173/6220. Acesso em: 5 nov. 2017.

Argum., Vitória, v. 10, n. 1, p. 118-132, jan./abr. 2018. 
SOARES, R. C. Contrarreforma na política de saúde e prática profissional do serviço social nos anos 2000. In: MOTA, A. E. (Org.). As ideologias da contrarreforma e o serviço social. Recife: Universitária; UFPE, 2010. p. 337-382.

SODRÉ, F. Serviço Social e o campo da saúde: para além de plantões e encaminhamentos. Revista Serviço Social e Sociedade, São Paulo, n. 103, p. 453-475, jul./set. 2010.

STARFIELD, B. Atenção Primária: equilíbrio entre a necessidade de saúde, serviços e tecnologias. Brasília (DF): UNESCO; Ministério da Saúde, 2002.

VIANA, A. L. D.; DAL POZ, M. Q. A Reforma do Sistema de Saúde no Brasil e o Programa de Saúde da Família. Physis, Rio de Janeiro, n. 15, Suplemento, p. 225-264, 2005.

Débora MARTINI. Participou da concepção, do delineamento e da redação do artigo.

Graduada em Serviço Social pela UFSC. Especialização em Saúde da Família/Modalidade Residência (20072009) e em Gestão da Saúde Pública (2012) pela UFSC. Mestre em Serviço Social pela UFSC. Preceptora do Curso de Residência Multiprofissional em Saúde da Família pela UFSC/SMS).

Keli Regina DAL PRÁ. Participou da concepção, do delineamento e da redação do artigo.

Graduação em Serviço social pela PUCRS. Mestre e Doutora pela PUCRS. Tem experiência na área de Serviço Social, atuando principalmente no tema de formação profissional, e na área de Saúde Coletiva nos temas de direito à saúde, saúde em áreas de fronteira, saúde no Mercosul e saúde pública. Integrante do Núcleo de Pesquisa Interdisciplinar Sociedade, Família e Políticas Sociais (NISFAPS) e da Rede de Pesquisa Família e Política social (REFAPS). 